\title{
Anatomy of Mandibular Vital Structures. Part I: Mandibular Canal and Inferior Alveolar Neurovascular Bundle in Relation with Dental Implantology
}

\author{
Gintaras Juodzbalys ${ }^{1}$, Hom-Lay Wang ${ }^{2}$, Gintautas Sabalys ${ }^{1}$ \\ ${ }^{1}$ Department of Oral and Maxillofacial Surgery, Kaunas University of Medicine, Lithuania \\ ${ }^{2}$ Department of Periodontics and Oral Medicine, University of Michigan, Ann Arbor Michigan, USA
}

\author{
Corresponding Author: \\ Gintaras Juodzbalys \\ Vainiku 12 \\ LT- 46383, Kaunas \\ Lithuania \\ Phone: +370 37297055 \\ Fax: +37037323153 \\ E-mail: gintaras@stilusoptimus.lt
}

\begin{abstract}
Objectives: It is critical to determine the location and configuration of the mandibular canal and related vital structures during the implant treatment. The purpose of the present paper was to review the literature concerning the mandibular canal and inferior alveolar neurovascular bundle anatomical variations related to the implant surgery.

Material and Methods: Literature was selected through the search of PubMed, Embase and Cochrane electronic databases. The keywords used for search were mandibular canal, inferior alveolar nerve, and inferior alveolar neurovascular bundle. The search was restricted to English language articles, published from 1973 to November 2009. Additionally, a manual search in the major anatomy, dental implant, prosthetic and periodontal journals and books were performed.

Results: In total, 46 literature sources were obtained and morphological aspects and variations of the anatomy related to implant treatment in posterior mandible were presented as two entities: intraosseous mandibular canal and associated inferior alveolar neurovascular bundle.

Conclusions: A review of morphological aspects and variations of the anatomy related to mandibular canal and mandibular vital structures are very important especially in implant therapy since inferior alveolar neurovascular bundle exists in different locations and possesses many variations. Individual, gender, age, race, assessing technique used and degree of edentulous alveolar bone atrophy largely influence these variations. It suggests that osteotomies in implant dentistry should not be developed in the posterior mandible until the position of the mandibular canal is established.
\end{abstract}

Keywords: mandible; alveolar nerve, inferior; anatomy; radiography; anatomy, cross-sectional; dental implants.

Accepted for publication: 31 December 2009

To cite this article:

Juodzbalys G, Wang HL, Sabalys G. Anatomy of Mandibular Vital Structures. Part I: Mandibular Canal and Inferior Alveolar Neurovascular Bundle in relation with Dental Implantology.

J Oral Maxillofac Res 2010 (Jan-Mar);1(1):e2

URL: http://www.ejomr.org/JOMR/archives/2010/1/e2/e2ht.pdf

doi:10.5037/jomr.2010.1102 


\section{INTRODUCTION}

Placement of mandibular endosseous implants can be problematic especially in the area of neurovascular bundles. The complications, such as altered sensation, numbness and pain, often occurred if these vital structures, such as inferior alveolar nerve (IAN) and mental foramen, are not properly identified. In addition, damage of related blood vessels (e.g., inferior alveolar or lingual artery) may trigger excessive bleeding. Damage to these vital structures is often arising from clinicians' surgical mistakes as well as fails to identify these structures [1]. Hence, it is critical to determine the location and configuration of the mandibular canal (MC) and related anatomical structures so these types of damages can be minimized [2]. Authors are planning to publish series of articles related to basic anatomy of mandibular vital structures, its practical application, diagnostic methods, possible damage and treatment at some stage in oral surgery procedures, mainly focused on dental implantology. Therefore, the purpose of the present study was to review the literature concerning the mandibular canal and inferior alveolar neurovascular bundle anatomical variations related to implant surgery.

\section{MATERIAL AND METHODS}

Literature was selected through a search of PubMed, Embase and Cochrane electronic databases. The keywords used for search were mandibular canal, and inferior alveolar neurovascular bundle. The search was restricted to English language articles, published from 1973 to November 2009. Additionally, a manual search in the major anatomy, dental implant, prosthetic and periodontal journals and books were performed. The publications there selected by including clinical and human anatomy studies. To make it easier for readers, the morphology and variations of the MC and inferior alveolar neurovascular bundle were presented as two entities: intraosseous mandibular canal and associated inferior alveolar neurovascular bundle.

\section{Anatomy of the mandibular canal (MC)}

The MC is a canal within the mandible that is beginning in mandibular foramen on the medial surface of the ascending mandibular ramus. It runs obliquely downward and forward in the ramus, and then horizontally forward in the body till mental foramen. It carries inferior alveolar neurovascular bundle [3]. The study of Rajchel et al. [4] on 45 Asian adults demonstrated that the $\mathrm{MC}$, when proximal to the third molar region, is usually a single large structure, 2.0 to $2.4 \mathrm{~mm}$ in diameter. Measurement obtained from 105 cadaver mandibles, Obradovic et al. [5] found the average diameter of the MC in its horizontal part is $2.6 \mathrm{~mm}$. Ikeda et al. [] conducted similar cadaver study and reported that canal is approximately $3.4 \mathrm{~mm}$ wide. Sato et al. [7] examined 75 adult Japanese cadavers' mandibles and concluded that vertical diameter of MC was about $5 \mathrm{~mm}$. Anterior to the mental foramen the $\mathrm{MC}$ is referred to as the incisive canal [8-13].

The anatomic features of the ascent of the canal as well as its buccolingual relationships have been studied extensively [14-17].

It was mentioned that the MC might have different anatomic configurations in the vertical plane. For example, the canal may run lower when it proceeds anteriorly, or may have sharp decline, or drape downward in catenary's fashion (Figure 1). The position in the vertical plane of the $\mathrm{MC}$ was evaluated from 3612 radiographs [18]. The MC, which houses the IAN, appears as a dark ribbon of radiolucency flanked by two radiopaque white lines. The radiographs were divided into four categories: 1) high MC (within $2 \mathrm{~mm}$ of the apices of the first and second molars), 2) intermediate MC, 3) low MC, and 4) other variations - these included duplication or division of the canal, apparent partial or complete absence of the canal or lack of symmetry (Figure 1). Of the 3612 radiographs, $48 \%$ of the canals were high, $49 \%$ were low, and only $3 \%$ could not be fitted into the high or low canal categories. The main conclusion of this study was that the MC are usually, but not invariably, bilaterally symmetrical, and the majority of hemi-mandibles contain only one major canal.

It is interesting to emphesize that MC bifurcates in the inferior superior or medial lateral plane in about $1 \%$ of patients. Duplication or division of the canal was found, via panoramic radiographs, in $0.9 \%$ (33/3612) of the cases in otherwise normal patients [18]. In another study, only $0.08 \%$ bifurcation of the IAN was found in 5000 US Army recruits, aged 17 to 26 [19]. Furthermore, Langlais and co-workers [20] evaluated routine panoramic radiographs of 6000 patients, and they found $57(0.95 \%)$ cases of bifid inferior MC, 19 in males and 38 in females. Sanchis et al. [21] analyzed panoramic radiographs of 2012 patients and reported that $0.35 \%$ of canals were bifid. All cases were registered in women. Claeys and Wackens [22] thought that bifid MC is often unrecognized. Naitoh et al. [23] used reconstructed computed tomography (CT) images to identify the bifid MC. They showed 4 (out of 5) sides had the bifid MC that possessed a short and narrow upper canal toward the distal area of the second molar while the remaining 1 side had a short and narrow lower canal toward 

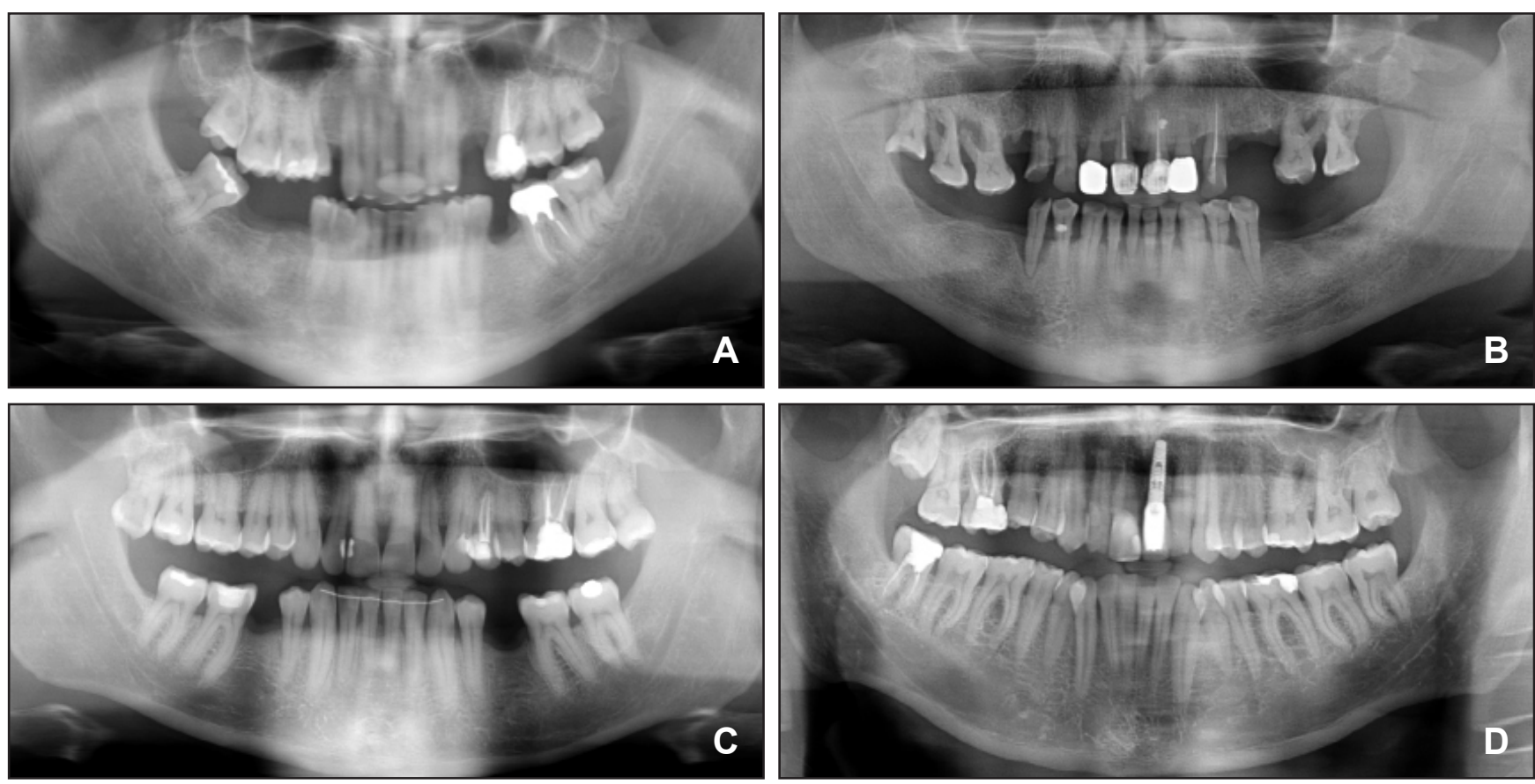

Figure 1. Panoramic radiographs showing different anatomic configurations (I) and position in the vertical plane (II) of the mandibular canal (MC).

I. Classification by Anderson et al. [16]: $\mathrm{A}=\mathrm{a}$ steep ascent from anterior to posterior; $\mathrm{B}=$ a gentle, progressive curve rising from anterior to posterior; $\mathrm{C}$ and $\mathrm{D}=$ a catenary-like canal.

II. Classification by Nortje et al. [18]: $\mathrm{A}=$ a high $\mathrm{MC}$ (within $2 \mathrm{~mm}$ of the apices of the first and second molars); $\mathrm{B}=$ an intermediate $\mathrm{MC}$; $\mathrm{C}=\mathrm{a}$ low $\mathrm{MC} ; \mathrm{D}=$ other variations (duplication or division of the $\mathrm{MC}$, apparent partial or complete absence of the canal or lack of symmetry).

the distal area of second molar. In the second study, Naitoh et al. [24] reconstructed 122 two-dimensional images of various planes in the mandibular ramus region to the computer program using three-dimensional visualization and measurement software. Bifid $\mathrm{MC}$ in the mandibular ramus region was observed in $65 \%$ of patients and $43 \%$ of sides. Furthermore, they classified bifid MC into four types: retromolar, dental, forward, and buccolingual canals. This finding confirmed importance of MC diagnostic method reliability.

Table 1 lists how the method of radiological examination influenced the occurrence of bifid MC. Auluck et al. [르] using panoramic radiographs reported bifid $\mathrm{MC}$ existed in 5 (out of 6) cases and trifid was noted in the remaining 1 case. Karamifar et al. [26] reported 2 cases with bilateral bifid MC. It has been mentioned that from an embryological perspective, there might be three inferior dental nerves innervating three groups of mandibular teeth [27]. How was the bifid/trifid MC formed? This has been hypothesized as following: during embryonic development a rapid prenatal growth and remodeling in the ramus region leads to intramembranous ossification that forms MC. The occurrence of bifid/trifid MC is thought to be secondary to the incomplete fusion of these three nerves. Once the multiple canals are identified, the local anaesthetic injection technique, and surgical procedures can be modified to prevent pain, discomfort or even numbness during treatment.

The more detailed vertical position of the MC was evaluated using either root apices of mandibular teeth and inferior border of mandible as anatomical landmark. Thus, Heasman [료] reported, from a study of 96 plain films of dried mandibles, that in $68 \%$ of cases the MC passed along an intermediate course between the mandibular root apices and the inferior border of the mandible. A mean distance of $10 \mathrm{~mm}$ between the $\mathrm{MC}$ and the inferior mandibular border, proximally to the third molar region has been reported [4]. It has also been shown the upper border of the MC was

Table 1. Percentage of occurrence of the bifid mandibular canal depending on radiological method of examination

\begin{tabular}{lccc}
\hline \multicolumn{1}{c}{ Study } & $\begin{array}{c}\text { Radiological examination } \\
\text { method }\end{array}$ & N & $\begin{array}{c}\text { Bifid } \\
\text { MC }\end{array}$ \\
\hline Nortje et al. (1977) & PR & 3612 & 0.9 \\
Grover and Lorton (1983) & PR & 5000 & 0.08 \\
Langlais et al. (1985) & PR & 6000 & 0.95 \\
Sanchis et al. (2003) & PR & 2012 & 0.35 \\
Naitoh et al. (2009) & CBCT & 212 & 65 \\
\hline
\end{tabular}

$\mathrm{MC}=$ mandibular canal; $\mathrm{PR}=$ panoramic radiographs $; \mathrm{CBCT}=$ cone beam computed tomography. 
located 3.5 to $5.4 \mathrm{~mm}$ below the root apices of the first and second molars [29]. Denio et al. [30] evaluated 22 cadavers and found the mean distance of the MC to the apices of mandibular second molar, the first molar and premolars were $3.7,6.9$, and $4.7 \mathrm{~mm}$, respectively. Sato with coauthors [7] defined the presence and course of the $\mathrm{MC}$ using macroscopic cadaveric dissection and CT or panoramic X-ray observation. Panoramic X-ray observation revealed that the vertical position of MC was closer to the apices of the first and the second molars than that to the distance of inferior border of mandible. The MC position was measured within $30 \%$ of ratio from the distance of inferior border of mandible to the apices of the roots (mesial root of the first molar: $20 \%$; distal root of the first molar: $22.6 \%$; mesial root of the second molar: $27.8 \%$ and distal root of the second molar: $47 \%$ ) on panoramic X-ray observation. In one cadaver (male, 64 years old) the main trunks of the inferior alveolar artery, vein, and nerve were in tight contact with the apex of the second molar.

When the mandibular teeth are lost, the alveolar bone that housed them resorbs in a varying degree $[\underline{31}, \underline{32}]$. All classic descriptions of the MC course mentioned above refer to dentate mandibles. In course of mandible atrophy, the dental ridge becomes lower, and this is why Levine et al. [33] measured the distance from the edentulous alveolar crest to the superior aspect of the MC of 50 patients who had a radiographically identifiable $\mathrm{MC}$ and at least one mandibular first molar. Results showed that the superior aspect of the MC was $17.4 \mathrm{~mm}$ inferior from the alveolar crest. Similarly, Watanabe et al. [34] analyzed CT data of 79 Japanese patients (52 male and 27 female) and found that the distance from the alveolar crest to the MC ranged from 15.3 to $17.4 \mathrm{~mm}$. It is clear that the distance between the MC and the atrophic alveolar ridge is variable dimension and should be assessed in each particular case.

It was reported that MC might have different anatomic configurations in the horizontal plane. Usually the MC crosses from the lingual to the buccal side of the mandible and in most cases the midway between the bucal and lingual cortical plates of bone is by the first molar [35-37]. According to Rajchel et al. [4], the $\mathrm{MC}$, when proximal to the third molar region, courses approximately $2.0 \mathrm{~mm}$ from the inner lingual cortex, 1.6 to $2.0 \mathrm{~mm}$ from the medial aspect of the buccal plate. Levine et al. [33] assessed MC bucolingual course for 50 patients. The mean buccal aspect of the canal was 4.9 $\mathrm{mm}$ from the buccal cortical margin of the mandible. Age and race were statistically associated with MC position relate to the buccal cortical mandibular margin $(\mathrm{P}<0.05)$. Older patients and white patients, on average, have less distance between the buccal aspect of the canal and the buccal mandibular border.

Kim et al. [38] classified the buccolingual location of the MC into 3 types: type 1 (70\%), where the canal follows the lingual cortical plate at the mandibular ramus and body; type $2(15 \%)$, where the canal follows the middle of the ramus behind the second molar and the lingual plate passing through the second and first molars; and type 3 (15\%), where the canal follows the middle or the lingual one third of the mandible from the ramus to the body.

\section{Inferior alveolar neurovascular bundle}

The mandibular nerve is the third and inferior to the most division of the trigeminal nerve, or the fifth cranial nerve. The lower branch is called the mandibular nerve [39]. The nerve enters the mandible through the mandibular foramen on the medial surface of the ascending mandibular ramus. After passing through the mandibular foramen, the nerve is called the inferior alveolar nerve. In the molar region, the IAN divides into the mental and mandibular incisal nerves $[\underline{8}, \underline{40}]$.

Within the MC, the IAN runs forwards in company with the inferior alveolar artery, vein, and lymphatic vessels and together they are called the inferior alveolar neurovascular bundle. The artery lies parallel to the nerve as it traverses anteriorly, but its position varies with respect to being superior to the nerve within the MC [41]. According to the report of Gowgiel [17], the neurovascular bundle from the mandibular foramen to the mental foramen is always in contact with, or in close proximity to the lingual mandibular cortex. It has been shown that vascular and nerve bundles may be extremely close to the buccal cortex of the mandible in patients with broad and thick mandibular rami. In the study of Tamas [15], this buccal position of the IAN was observed in $6 \%(10 / 164)$ of the mandibles. Kim et al. [38] in three-dimensional reconstruction of 10 canals revealed that the inferior alveolar vessel travelled above the IAN in 8 cases $(80 \%)$, with the inferior alveolar artery being lingual to the inferior alveolar vein, and in 2 cases $(20 \%)$ where the inferior alveolar vessel was buccal to the nerve. Pogrel et al. [42] dissected the inferior alveolar neurovascular bundle in the region of third molar from 8 cadaveric mandibles and examined clinically and histologically for the arrangement of the inferior alveolar artery, vein, and nerve. It was confirmed that the inferior alveolar vein lies superior to the nerve and that there are often multiple veins. The artery appears to be solitary and lies on the lingual side of the nerve, slightly above the horizontal position. This position appeared to be consistent in all cases.

Despite a number of anatomical descriptions of the IAN, there is no consensus on its course and 
pattern of its distribution [43]. Traditionally there are two methods of IAN course and pattern investigation: cadavers study and medical imagination methods. First attempt to classify the IAN anatomy was provided by Olivier in 1928 [44]. He described two typical patterns based on the dissection of 50 mandibles: in Type I, the IAN was a single structural entity with branches to the individual teeth, and was observed in $66 \%$ of cases; in Type II, observed in $34 \%$ of cases, the IAN formed a plexus from which individual teeth were supplied. Carter and Keen [45], who studied 8 human mandibles, classified the IAN into three categories: the most common category consisted of a single nerve trunk that coursed directly beneath the apices of the mandibular teeth; the second category consisted of a large nerve from which individual nerves supplied the lower teeth; and the third category consisted of a nerve trunk superior to which there was a plexus that supplied the teeth. Wadu et al. [40] dissected 29 human mandibles and found that the nerve trunk divided into a plexus in the molar area in all cases.

Polland et al. [32] studied the anatomy of the IAN in the edentulous human jaw. They examined 7 mandibles and found a single large nerve bundle in each case. Kieser et al. [43] investigated the vertical positioning and intrabony branching patterns of the IAN in 39 edentulous human cadaveric mandibles by buccal microdissection. Dissected mandibles were classified on the basis of the height of the IAN within the body of the mandible and the branching pattern of the IAN. The IAN was located in the superior part of the body of the mandible in $30.7 \%$ (12/39) of cases, all of which showed a small posterior molar plexus of branches. In $69.2 \%(27 / 39)$, the IAN was half-way or closer to the inferior border of the mandible. All of these latter cases, $41 \%$ demonstrated a small, posterior molar plexus of branches, 37\% showed posterior and anterior plexuses, and $22 \%$ had either no branches or a single trunk with a small number of single branches directed at the superior border of the mandible (Figure 2).

Ikeda et al. [41] in their cadaveric study measured the IAN thickness and concluded that it is around $2.2 \mathrm{~mm}$ thick. Moriyama with coauthors [46] morphometrically analyzed the human IAN from 22 dentate cadavers (11 female and 11 male). They estimated the average total number of myelinated axons in the female IAN to be 25,230 , with an average transverse area of $34.1 \mu \mathrm{m}^{2}$, an average perimeter of $21.8 \mu \mathrm{m}$, and an average circularity ratio of 0.86 , while in male IAN numbers as following: $20,278,31.7 \mu \mathrm{m}^{2}$, $20.7 \mu \mathrm{m}$, and 0.87 , respectively. The data showed no significant difference between the female and male specimens in any measured items $(\mathrm{P}>0.05)$.

The IAN supplies the mandibular molar and

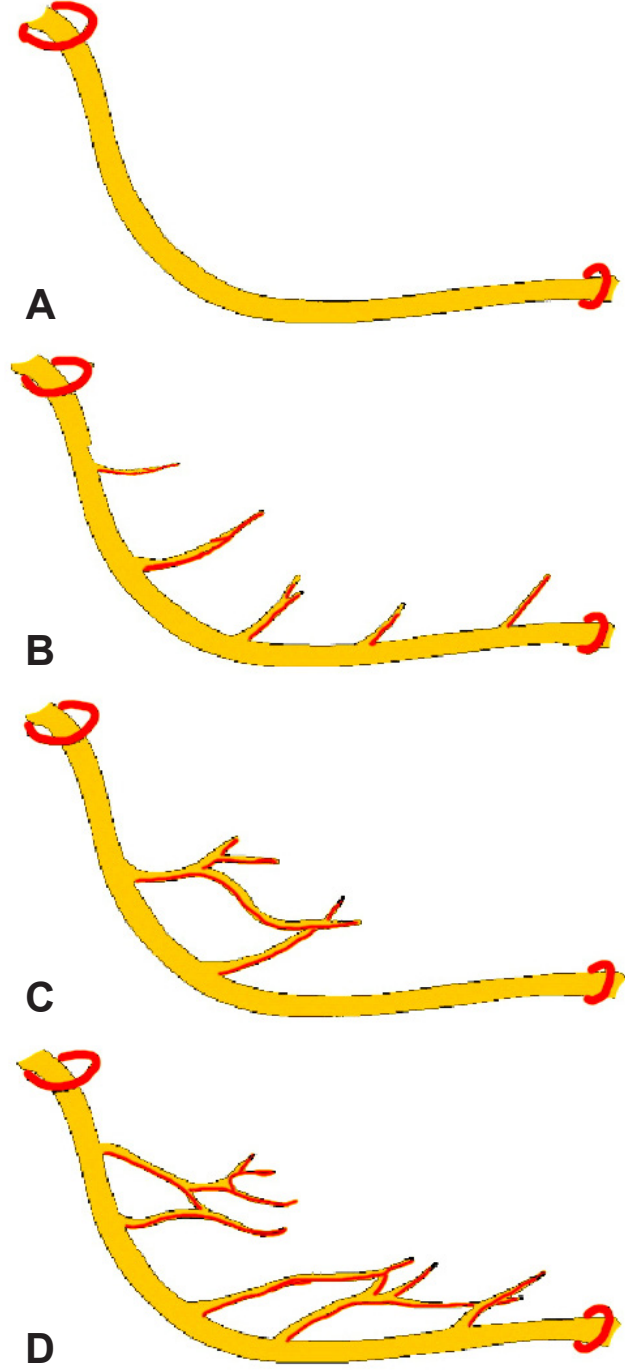

Figure 2. Branching patterns of the IAN: classification by Kieser et al. [43]. $\mathrm{A}=$ single unbranched nerve; $\mathrm{B}=$ series of individual branches to the superior border of the mandible; $\mathrm{C}=$ fine molar plexus. $\mathrm{D}=$ proximal and distal nerve plexus.

premolar teeth and adjacent parts of the gingiva. Its larger terminal branch emerges from the mental foramen as the mental nerve. Three nerve branches come out of the mental foramen [10]. One innervates the skin of the mental area, and the other two proceed to the skin of the lower lip, mucous membranes, and the gingiva as far posteriorly as the second premolar. The incisive branch, a continuation of the IAN, supplies the canine and incisor teeth [10].

\section{CONCLUSIONS}

1. In approximately $49 \%$ of cases mandibular canal and inferior alveolar neurovascular bundle has low vertical position and there is sufficient alveolar ridge height for osteotomy development over the mandibular canal. However in course of mandible atrophy, the dental ridge becomes lower to different degree in each particular 
case. Furthermore in $48 \%$ of cases mandibular canal vertical position was diagnosed as high.

2. In $70 \%$ of cases the mandibullar canal and inferior alveolar neurovascular bundle stretches throughout the mandible body forming an "S" shape curve. It approaches the lingual surface of the mandible in the area of the molars, and, stretching forwards to the front part, comes closer to the vestibulum surface. In order to plan a proper dental implantation method and select implants of a relevant type, it is important to be aware of the position of the mandibular canal in connection with the side compact lamellas.

3. Depending on method of investigation in about 0.08 to $65 \%$ of patients, the mandibular canal bifurcates in the inferior superior or medial lateral plane. The detection of these anatomical variations is important because of its clinical implications such as the ineffective mandibular block or numbness noted in the lower jaw after implant surgery.

4. Inferior alveolar neurovascular bundle exists in different locations and possesses many variations. Individual, gender, age, race, assessing technique used and degree of edentulous alveolar bone atrophy largely influence these variations.

5. Osteotomies in implant dentistry should not be developed in the posterior mandible until the position of the mandibular canal is established.

\section{ACKNOWLEDGMENTS AND DISCLOSURE STATEMENTS}

The authors report no conflicts of interest related to this study.

\section{REFERENCES}

1. Kim IS, Kim SG, Kim YK, Kim JD. Position of the mental foramen in a Korean population: a clinical and radiographic study. Implant Dent. 2006 Dec;15(4):404-11. [Medline: 17172959] [doi: 10.1097/01.id.0000243319.66845.15]

2. Rueda S, Gil JA, Pichery R, Alcañiz M. Automatic segmentation of jaw tissues in CT using active appearance models and semi-automatic landmarking. Med Image Comput Comput Assist Interv. 2006;9(Pt 1):167-74. [Medline: 17354887] [doi: $10.1007 / 11866565 \quad 21]$

3. Tammisalo T, Happonen RP, Tammisalo EH. Stereographic assessment of mandibular canal in relation to the roots of impacted lower third molar using multiprojection narrow beam radiography. Int J Oral Maxillofac Surg. 1992 Apr;21(2):85-9. [Medline: 1602166] [doi: 10.1016/S0901-5027(05)80538-7]

4. Rajchel J, Ellis E 3rd, Fonseca RJ. The anatomical location of the mandibular canal: its relationship to the sagittal ramus osteotomy. Int J Adult Orthodon Orthognath Surg. 1986 Winter;1(1):37-47. [Medline: 3457874]

5. Obradovic O, Todorovic L, Pesic V, Pejkovic B, Vitanovic V. Morphometric analysis of mandibular canal: clinical aspects. Bull Group Int Rech Sci Stomatol Odontol. 1993 Jul-Sep;36(3-4):109-13. [Medline: 8219689]

6. Ikeda K, Ho KC, Nowicki BH, Haughton VM. Multiplanar MR and anatomic study of the mandibular canal. AJNR Am J Neuroradiol. 1996 Mar;17(3):579-84. [Medline: 8881258] [FREE Full Text]

7. Sato I, Ueno R, Kawai T, Yosue T. Rare courses of the mandibular canal in the molar regions of the human mandible: a cadaveric study. Okajimas Folia Anat Jpn. 2005 Nov;82(3):95-101. [Medline: 16350422] [doi: 10.2535/ofaj.82.95]

8. Mardinger O, Chaushu G, Arensburg B, Taicher S, Kaffe I. Anterior loop of the mental canal: an anatomical-radiologic study. Implant Dent. 2000;9(2):120-5. [Medline: 11307391] [doi: 10.1097/00008505-200009020-00003]

9. De Andrade E, Otomo-Corgel J, Pucher J, Ranganath KA, St George N Jr. The intraosseous course of the mandibular incisive nerve in the mandibular symphysis. Int J Periodontics Restorative Dent. 2001 Dec;21(6):591-7. [Medline: 11794570]

10. Mraiwa N, Jacobs R, Moerman P, Lambrichts I, van Steenberghe D, Quirynen M. Presence and course of the incisive canal in the human mandibular interforaminal region: two-dimensional imaging versus anatomical observations. Surg Radiol Anat. 2003 Nov-Dec;25(5-6):416-23. Epub 2003 Sep 11. [Medline: 13680184] [doi: 10.1007/s00276-003-0152-8]

11. Jacobs R, Mraiwa N, Van Steenberghe D, Sanderink G, Quirynen M. Appearance of the mandibular incisive canal on panoramic radiographs. Surg Radiol Anat. 2004 Aug;26(4):329-33. Epub 2004 Jun 10. [Medline: 15197490] [doi: 10.1007/s00276-004-0242-2]

12. Uchida Y, Yamashita Y, Goto M, Hanihara T. Measurement of anterior loop length for the mandibular canal and diameter of the mandibular incisive canal to avoid nerve damage when installing endosseous implants in the interforaminal region. J Oral Maxillofac Surg. 2007 Sep;65(9):1772-9. [Medline: 17719396] [doi: 10.1016/j.joms.2006.10.015]

13. Uchida Y, Noguchi N, Goto M, Yamashita Y, Hanihara T, Takamori H, Sato I, Kawai T, Yosue T. Measurement of anterior loop length for the mandibular canal and diameter of the mandibular incisive canal to avoid nerve damage when installing endosseous implants in the interforaminal region: a second attempt introducing cone beam computed tomography. J Oral Maxillofac Surg. 2009 Apr;67(4):744-50. [Medline: 19304029] [doi: 10.1016/j.joms.2008.05.352]

14. Mercier P. The inner osseous architecture and the sagittal splitting of the ascending ramus of the mandible. J Maxillofac Surg. 1973 Sep;1(3):171-6. [Medline: 4520655] [doi: 10.1016/S0301-0503(73)80035-9] 
15. Tamás F. Position of the mandibular canal. Int J Oral Maxillofac Surg. 1987 Feb;16(1):65-9. [Medline: 3104497] [doi: 10.1016/S0901-5027(87)80032-2]

16. Anderson LC, Kosinski TF, Mentag PJ. A review of the intraosseous course of the nerves of the mandible. J Oral Implantol. 1991;17(4):394-403. [Medline: 1813647]

17. Gowgiel JM. The position and course of the mandibular canal. J Oral Implantol. 1992;18(4):383-5. [Medline: 1298823]

18. Nortjé CJ, Farman AG, Grotepass FW. Variations in the normal anatomy of the inferior dental (mandibular) canal: a retrospective study of panoramic radiographs from 3612 routine dental patients. Br J Oral Surg. 1977 Jul;15(1):55-63. [Medline: 268217] [doi: 10.1016/0007-117X(77)90008-7]

19. Grover PS, Lorton L. Bifid mandibular nerve as a possible cause of inadequate anesthesia in the mandible. J Oral Maxillofac Surg. 1983 Mar;41(3):177-9. [Medline: 6572228] [doi: 10.1016/0278-2391(83)90076-9]

20. Langlais RP, Broadus R, Glass BJ. Bifid mandibular canals in panoramic radiographs. J Am Dent Assoc. 1985 Jun;110(6):923-6. [Medline: 3860553]

21. Sanchis JM, Peñarrocha M, Soler F. Bifid mandibular canal. J Oral Maxillofac Surg. 2003 Apr;61(4):422-4. [Medline: 12684957] [doi: 10.1053/joms.2003.50004]

22. Claeys V, Wackens G. Bifid mandibular canal: literature review and case report. Dentomaxillofac Radiol. 2005 Jan;34(1):55-8. [Medline: $\underline{15709108]}$ [doi: $\underline{10.1259 / \mathrm{dmfr} / 23146121]}$

23. Naitoh M, Hiraiwa Y, Aimiya H, Gotoh K, Ariji E. Accessory mental foramen assessment using cone-beam computed tomography. Oral Surg Oral Med Oral Pathol Oral Radiol Endod. 2009 Feb;107(2):289-94. Epub 2008 Dec 13. [Medline: 19071039] [doi: 10.1016/j.tripleo.2008.09.010]

24. Naitoh M, Hiraiwa Y, Aimiya H, Ariji E. Observation of bifid mandibular canal using cone-beam computerized tomography. Int J Oral Maxillofac Implants. 2009 Jan-Feb;24(1):155-9. [Medline: 19344041]

25. Auluck A, Pai KM, Mupparapu M. Multiple mandibular nerve canals: radiographic observations and clinical relevance. Report of 6 cases. Quintessence Int. 2007 Oct;38(9):781-7. [Medline: 17873985]

26. Karamifar K, Shahidi S, Tondari A. Bilateral bifid mandibular canal: report of two cases. Indian J Dent Res. 2009 AprJun;20(2):235-7. [Medline: 19553729] [FREE Full Text] [doi: 10.4103/0970-9290.52889]

27. Wadhwani P, Mathur RM, Kohli M, Sahu R. Mandibular canal variant: a case report. J Oral Pathol Med. 2008 Feb;37(2):122-4. [Medline: 18197857]

28. Heasman PA. Variation in the position of the inferior dental canal and its significance to restorative dentistry. J Dent. 1988 Feb;16(1):36-9. [Medline: 3164005] [doi: 10.1016/0300-5712(88)90102-9]

29. Littner MM, Kaffe I, Tamse A, Dicapua P. Relationship between the apices of the lower molars and mandibular canal--a radiographic study. Oral Surg Oral Med Oral Pathol. 1986 Nov;62(5):595-602. [Medline: $\underline{3466132}$ ]

30. Denio D, Torabinejad M, Bakland LK. Anatomical relationship of the mandibular canal to its surrounding structures in mature mandibles. J Endod. 1992 Apr;18(4):161-5. [Medline: 1402570] [doi: 10.1016/S0099-2399(06)81411-1]

31. Lavelle CL. Preliminary study of mandibular shape after tooth loss. J Prosthet Dent. 1985 May;53(5):726-30. [Medline: 3858541] [doi: 10.1016/0022-3913(85)90033-2]

32. Polland KE, Munro S, Reford G, Lockhart A, Logan G, Brocklebank L, McDonald SW. The mandibular canal of the edentulous jaw. Clin Anat. 2001 Nov;14(6):445-52. [Medline: 11754239] [doi: 10.1002/ca.1080]

33. Levine $\mathrm{MH}$, Goddard AL, Dodson TB. Inferior alveolar nerve canal position: a clinical and radiographic study. J Oral Maxillofac Surg. 2007 Mar;65(3):470-4. [Medline: 17307595] [doi: 10.1016/j.joms.2006.05.056]

34. Watanabe H, Mohammad Abdul M, Kurabayashi T, Aoki H. Mandible size and morphology determined with CT on a premise of dental implant operation. Surg Radiol Anat. 2009 Oct 8. [Epub ahead of print] [Medline: 19812884] [doi: 10.1007/s00276-009-0570-3]

35. Miller CS, Nummikoski PV, Barnett DA, Langlais RP. Cross-sectional tomography. A diagnostic technique for determining the buccolingual relationship of impacted mandibular third molars and the inferior alveolar neurovascular bundle. Oral Surg Oral Med Oral Pathol. 1990 Dec;70(6):791-7. [Medline: 2263343]

36. Obradović O, Todorovic L, Vitanovic V. Anatomical considerations relevant to implant procedures in the mandible. Bull Group Int Rech Sci Stomatol Odontol. 1995 Jan-Feb;38(1-2):39-44. [Medline: 7881265]

37. Davis H. Mobilization of the Alveolar Nerve to Allow Placement of Osseointegratible Fixtures. In: Advanced Osseointegration Surgery: Application in the Maxillofacial Region. Chicago: Quintessence Publishing Co.: 2000: 129-141.

38. Kim ST, Hu KS, Song WC, Kang MK, Park HD, Kim HJ. Location of the mandibular canal and the topography of its neurovascular structures. J Craniofac Surg. 2009 May;20(3):936-9. [Medline: 19461335]

39. Gosling JA, Harris PF, Humpherson JR, Whitmore I \& Willan PLT. Head and neck. In: Atlas of human anatomy with integrated text. Edinburgh-London-New York: Churchill Livingstone; 1985. p. 250-290.

40. Wadu SG, Penhall B, Townsend GC. Morphological variability of the human inferior alveolar nerve. Clin Anat. 1997;10(2):82-7. [Medline: 9058013] [doi: 10.1002/(SICI)1098-2353(1997)10:2<82::AID-CA2>3.0.CO;2-V]

41. Ikeda K, Ho KC, Nowicki BH, Haughton VM. Multiplanar MR and anatomic study of the mandibular canal. AJNR Am J Neuroradiol. 1996 Mar;17(3):579-84. [Medline: 8881258] [FREE Full Text]

42. Pogrel MA, Dorfman D, Fallah H. The anatomic structure of the inferior alveolar neurovascular bundle in the third molar region. J Oral Maxillofac Surg. 2009 Nov;67(11):2452-4. [Medline: 19837316] [doi: 10.1016/j.joms.2009.06.013] 
43. Kieser J, Kieser D, Hauman T. The course and distribution of the inferior alveolar nerve in the edentulous mandible. J Craniofac Surg. 2005 Jan;16(1):6-9. [Medline: 15699637]

44. Olivier E. The inferior dental canal and its nerve in the adult. Br Dent J. 1928 49:356 -358.

45. Carter RB, Keen EN. The intramandibular course of the inferior alveolar nerve. J Anat. 1971 Apr;108(Pt 3):433-40. [Medline: 5575310] [FREE Full Text]

46. Moriyama H, Shimada K, Itoh M, Takahashi T, Otsuka N. Morphometric analysis of the inferior alveolar nerve fails to demonstrate sexual dimorphism. J Oral Maxillofac Surg. 2007 Aug;65(8):1555-61. [Medline: 17656283] [doi: 10.1016/j.joms.2007.05.002]

\section{To cite this article:}

Juodzbalys G, Wang HL, Sabalys G. Anatomy of Mandibular Vital Structures. Part I: Mandibular Canal and Inferior Alveolar Neurovascular Bundle in relation with Dental Implantology.

J Oral Maxillofac Res 2010;1(1):e2

URL: http://www.ejomr.org/JOMR/archives/2010/1/e2/e2ht.pdf

doi:10.5037/jomr.2010.1102

Copyright (C) Juodzbalys G, Wang HL, Sabalys G. Accepted for publication in the JOURNAL OF ORAL \& MAXILLOFACIAL RESEARCH (http://www.ejomr.org), 31 December 2009.

This is an open-access article, first published in the JOURNAL OF ORAL \& MAXILLOFACIAL RESEARCH, distributed under the terms of the Creative Commons Attribution-Noncommercial-No Derivative Works 3.0 Unported License, which permits unrestricted non-commercial use, distribution, and reproduction in any medium, provided the original work and is properly cited. The copyright, license information and link to the original publication on (http://www.ejomr.org) must be included. 